\title{
LA PRODUCCIÓN DE LA NOTICIA EN TELEVISIÓN DE LOS CORRESPONSALES DE MÉXICO Y COLOMBIA EN ESPAÑA EN LOS AÑOS 90
}

Fernando Rozo Ardila (Universidad Complutense)

\section{Introducción}

Los años noventa marcaron una etapa importante para los corresponsales de Colombia y México en España. La bonanza económica permitía a los informativos contar con periodistas en el lugar de la noticia y Madrid era el centro base para cubrir informativamente toda lo que sucedía en Europa.

En el año de 1992, se crea en Madrid la empresa IBER PRESS TV, una productora que se encargará de ofrecer noticias a todos los informativos en Colombia. Participo en el nacimiento y desarrollo de esta nueva empresa en la que trabajo como corresponsal. Durante seis años como empleado de IBER PRESS TV, El autor de este artículo participa en el nacimiento y desarrollo de esta nueva empresa trabajando como corresponsal durante seis años e inmerso en la tarea de convertir los hechos en noticias ${ }^{1}$ realizando distintas funciones como ayudante de cámara, productor, redactor e investigador de los temas que se trataban para Colombia en diferentes informativos. Así mismo estuvo presente en charlas, entrevistas y coloquios con periodistas de la corresponsalía mexicana que desarrollaba su propio método de producción de noticias.

La casualidad hace que el nacimiento de la corresponsalía mexicana de TELEVISA en Madrid coincida con la de la productora colombiana IBER PRESS televisión en Madrid. Esto permite diferenciar la producción de la noticia en las dos empresas periodísticas, atendiendo a los criterios empleados por los corresponsales a la hora de seleccionar los temas, su estabilidad y credibilidad dentro de la empresa, sus fuentes consultadas, sus rutinas establecidas, su objetividad y los equipos empleados. Si se considera la noticia como una institución social, según explica

\footnotetext{
${ }^{1}$ GOMIS, Lorenzo. El Medio Media: La Función Política de la Prensa. “...el lenguaje es un modo de captación de la realidad que permite darle forma, aislar dentro de ella unos hechos a los que, por un procedimiento de redacción, se convierte en noticia". Seminarios y Ediciones. Madrid 1974. Pág. 24.
} 
Gaye Tuchman², debe preguntarse qué función desempeñan los corresponsales latinoamericanos que trabajan para estas empresas consolidadas que distribuyen la información y cuál es la diferencia de intereses entre dueños y empleados.

La planificación del trabajo en la corresponsalía mexicana se hacía con una semana de antelación y se escribía en una pizarra para que todo el equipo conociera las tareas respectivas. En IBER PRESS no existía una planificación diaria porque era imprevisible la petición de noticias por parte de los informativos en Colombia. Esta clase de noticias Tuchman la denomina noticia súbita "los sucesos de noticias súbitas están improgramados; aparecen súbitamente y deben ser procesados con rapidez"3.

Es importante recalcar que algunos corresponsales estaban capacitados para realizar el trabajo de cualquier compañero en el caso de verse obligados a reemplazarle en su tarea informativa. Es más, en la corresponsalía colombiana se hacía a diario sin detrimento del corresponsal titular. Diferente era la situación en ECO (Televisa), ya que las noticias fabricadas por el corresponsal jefe y las fuentes manejadas no eran de fácil acceso para sus compañeros de trabajo. Existía una jerarquía difícil de romper y compartir. Tuchman define esta situación desde la jerarquización del poder ${ }^{4}$.

En la presentación de las noticias cada corresponsal construye su relato de acuerdo a su objetividad, algo en constante disputa con la ideología del medio. Tuchman explica esta etapa de la producción de la noticia como "la interpretación que da el reportero de los hechos. Los lectores o telespectadores deben confiar y aceptar la información del reportero de acuerdo con su evaluación de las calificaciones y actitudes del reportero"

La corresponsalía de ECO se ubicó en una sede nueva, muy cerca al parque el retiro. Una oficina con todo lo necesario para realizar el trabajo en condiciones

2 TUCHMAN, Gaye. En primer término, la noticia es un método institucional para que la información esté disponible ante los consumidores... La producción de la noticia. Gustavo Gilli. Barcelona. 1987. Pág. 16-17.

3 TUCHMAN, Gaye. La producción de la noticia. Gustavo Gilli. Barcelona 1978. Pág. 66.

4 TUCHMAN, Gaye. Cuanto más alto sea el status de las fuentes y cuanto mayor el alcance de sus posiciones, tanto más alto es el status de los reporteros. Como es bien sabido, los relatos de noticias, las fuentes de noticias y los reporteros están dispuestos jerárquicamente. La producción de la noticia. Gustavo Gilli. Barcelona 1978. Pág. 81.

TUCHMAN, Gaye. La producción de la noticia. Gustavo Gilli. Barcelona 1978. Pág. 111. 
óptimas. Mientras que la sede de IBER PRESS TV se situaba en un piso de alquiler, con un solo ordenador para cinco o seis redactores.

Los viajes en ECO eran costeados por el propio corresponsal con la tarjeta visa de la empresa; en IBER PRESS TV, se hacía el viaje una vez aceptado el presupuesto, luego se facturaba el desplazamiento con los recibos de pago como justificante para que se abonaran desde Colombia a los tres meses de haberse efectuado.

\section{La producción de noticias}

Los periodistas de ECO comenzaban su jornada laboral a las nueve de la mañana y terminaban una vez las noticias se lanzaban a través del satélite, sobre las siete de la tarde, con una hora de descanso para comer. Por el contrario, el corresponsal o colaborador de IBER PRESS TV debía estar prevenido durante todo el día, porque el envío se realizaba después de las diez de la noche y siempre había algo que enviar a última hora a través del satélite de Televisión Española.

El proceso de producción de noticias también tiene varias etapas que se pueden encontrar en la búsqueda del acontecimiento, pero que desarrolla cada redactor. En su trabajo Mark Fishman describe la producción de la noticia pasando por 4 etapas:

1) DETECTAN ACONTECIMIENTOS: Estructura de la información, restricciones de los periodistas que trabajan en una empresa organizada o la pauta de rutinas laborales que constituyen la búsqueda de la noticia en su ámbito nacional.

2) LOS INTERPRETAN COMO SUCESOS SIGIFICATIVOS: ¿Por qué medios los periodistas interpretan lo que ven...cómo confieren sentido y significatividad los reporteros a las cosas con las cuales toman contacto?

3) INVESTIGAN SU CARÁCTER FÁCTICO: cuáles son los métodos de verificación y los criterios empleados por los periodistas para determinar los hechos.

4) LOS RECOPILAN O "MONTAN" EN NOTICIAS: condicionada por una visión ideológica ${ }^{6}$.

Los corresponsales de la televisión mexicana elaboraban diariamente noticias. En su rutina de trabajo no hay demasiado interés por conseguir información fuera de los círculos oficiales. En sus relatos reflejan el día a día de las noticias de portada de los

6 FISHMAN, Mark. La fabricación de la noticia. Ediciones tres tiempos. Argentina, 1983. Págs. 224$225-226$ 
periódicos españoles. Los reporteros de ECO no recorren las calles en busca de los hechos que pueden ser noticia, ni tampoco frecuentan las ruedas de prensa.

La situación que se desarrollaba con frecuencia en la corresponsalía mexicana ECO era enviar al operador de cámara junto a su ayudante a grabar el evento, para que haga algunas preguntas y regrese con el trabajo a la corresponsalía. Luego el corresponsal salía a grabar las entradillas, medianillas y salidillas.

A diferencia de los periodistas mexicanos, los corresponsales colombianos recibían desde Colombia los detalles de las posibles fuentes que debían consultar para asistir como observadores y valedores del acontecimiento.

Los corresponsales tanto de México como de Colombia observaban los hechos y a partir de los mismos construían sus propios relatos. Mark Fishman en su libro " La fabricación de la noticia" presenta cinco premisas para esta detección de los sucesos, que depende de los métodos para tomar contacto con éste, como de los esquemas para interpretar los posibles acaecimientos noticiables ${ }^{7}$.

Los periodistas que trabajan para informativos con sede en el extranjero buscan temas en exclusiva que puedan emitir antes que la cadena rival. Situación distinta es la de México, ya que con emitir lo que pasa en España horas antes es suficiente. ECO no necesita ni demanda temas en exclusiva para su labor diaria.

La corresponsalía colombiana solicitaba un envío a la hora señalada por los telediarios colombianos y lo hacía desde Televisión Española. Si no se entregaba la noticia a la hora prevista, perdía el envío y el trabajo realizado. Si lo hacía más tarde debían abonar los gastos de envío. Para ECO el reabrir la señal no tiene ningún coste. Porque lo hace desde su misma sede.

Jaime Barroso explica a grandes rasgos las tres fases del proceso que más incide en las corresponsalías y en los medios de comunicación. La recogida, la selección y presentación de las noticias.

"La recogida de las noticias hace referencia al modo y procedimientos mediante los cuales el medio hace acopio de las informaciones, siempre procurará que sean muchas más de las necesarias, y las vías o canales más habituales: las fuentes, las agencias y la agenda de previsiones... La Selección es el momento en que la información decide convertirse en noticia. Es la fase crítica, la aplicación de los criterios del valor-noticia y el ámbito de los "guardianes": los gatekeepers... La 
presentación es el ámbito propio del informador, del periodista y del equipo técnico ${ }^{8}$.

Barroso explica los problemas a los que se debe enfrentar un periodista de televisión en su rutina diaria: "físicos, ideológicos y económicos"'.

Estos inconvenientes que señala Barroso se observan y diferencian con bastante claridad en las dos corresponsalías hispanoamericanas.

Los problemas físicos son la primera dificultad con los que se encuentra el informador, retomando los conceptos a los que hace alusión Jaime Barroso García, ya que no siempre se puede acceder al sitio de los acontecimientos, salvo cuando se trata de convocatorias. Para las dos corresponsalías el movilizar un equipo de televisión se torna a veces una tarea compleja y difícil.

El equipo que se traslada en busca de la noticia está compuesto por un redactor, un operador de cámara y un ayudante de cámara, en lo que concierne a ECO, y un redactor o colaborador, acompañado de un operador de cámara, en lo que se refiere a IBER PRESS TV.

Los corresponsales de ECO utilizan el taxi casi en todas las salidas, agilizando el desplazamiento y la llegada al lugar de la noticia. La corresponsalía colombiana cuenta con el coche particular que proporciona más autonomía a los profesionales, pero dificulta la puntualidad ante la necesidad de aparcar.

El aspecto humano es la segunda dificultad a tener en cuenta, según Barroso, debido a que se necesitan redactores que posean la preparación técnica y psicológica necesaria, al igual que una experiencia y profesionalidad acreditada. Gaye Tuchman también considera fundamental la preparación del periodista si quiere ejercer como un buen profesional de la información: "para los informadores, la capacidad de construir narraciones es una capacidad profesional aprendida con anterioridad, mediante años de aprendizaje del oficio"10.

La tercera dificultad que plantea el Barroso en la producción de la noticia es la parte técnica. ECO contaba con dos cámaras. Una de ellas semiprofesional, con poca calidad, y la otra sí era una cámara profesional. IBER PRESS TV contó al principio con una sola cámara para todos los informativos, lo que conllevaba pérdida de

\footnotetext{
8 BARROSOS GARCIA, Jaime. Proceso de la Información de actualidad en televisión. Instituto Oficial de Radio y Televisión. IORTV. RTVE. Madrid 1992. Págs. 149-150.

9 BARROSOS GARCIA, Jaime. Proceso de la Información de actualidad en televisión. Instituto Oficial de Radio y Televisión. IORTV. RTVE. Madrid 1992. Pág. 152.

10 TUCHMAN, Gaye. La producción de la noticia. Gustavo Gilli. Barcelona 1978. Pág. 118.
} 
tiempo y de autonomía para cada corresponsal. El otro condicionante técnico es el envío de la noticia vía satélite a Colombia. Existen límites de tiempo muy cortos para concretar permisos y cuando se solicitaban, casi siempre después de las ocho de la tarde hora española, ya no trabajan los responsables de TVE en sus despachos, que son los únicos que tramitan administrativamente el enlace.

La cuarta dificultad es la ideológica o política. Cuando llegaban desde Colombia representantes políticos contrarios a los editoriales de los informativos no era necesario cubrir la noticia, aunque sí se debía hacerse eco de la visita. A veces las preguntas y respuestas eran pactadas desde la propia cadena en Colombia.

La quinta y última dificultad expuesta por Barroso es la económica. Las corresponsalías al contar con pocos recursos no pueden cubrir gran parte de la actualidad. En IBER PRESS TV se grababa la misma noticia para cuatro informativos distintos con una sola cámara. Sirva como ejemplo el concierto del cantante colombiano Carlos Vives en las Ventas: el compromiso era realizar una entrevista en exclusiva con el cantante y grabar tres canciones del concierto. Esto significaba que la misma cámara debía tomar imágenes desde cuatro ángulos distintos. El redactor jefe, Mauricio Hernández, fabrica la misma noticia tres veces con las mismas palabras.

Entre las dos corresponsalías México continúa con su producción propia sin necesidad de recurrir a las agencias para fabricar relatos. Los noticieros en Colombia siguen comprando a las agencias porque para ellos mantener un corresponsal es muy costoso y carecen de medios limitados.

Barrroso ya lo advertía: "La gran mayoría de las televisiones carecen del potencial económico suficiente para mantener una red estable de corresponsales que cubran, sino los países más importantes, al menos los puntos calientes de la información, y los enviados especiales con los que se trata de suplir esa limitación han de afrontar una carga añadida de dificultades de acceso por la falta de familiaridad y conocimiento del entorno, que con frecuencia devalúa su propio trabajo. Una vez más surgen argumentos para recurrir a la agencia antes que a la cobertura propia"11. Se debe considerar seriamente la autocrítica en el trabajo del corresponsal, ya que ayuda a la revisión colectiva de conciencias autocomplacientes en su tarea

11 BARROSOS GARCIA, Jaime. Proceso de la Información de actualidad en televisión. Instituto Oficial de Radio y Televisión. IORTV. RTVE. Madrid 1992. Págs. 153. 
informativa. En la mayoría de los casos se observa carencia de profesionalidad y una honestidad ambigua. El corresponsal atiende las órdenes de sus empresas y elabora un relato de acuerdo a los intereses de las mismas.

Los corresponsales o colaboradores de IBER PREES TV trabajaban con pocos minutos de margen entre la llamada de la cadena colombiana y la fabricación de la noticia. Para las grandes empresas televisivas de Colombia no era rentable económicamente mantener una corresponsalía estable en Madrid. Los costes elevados impiden que se cubra un gran volumen de noticias, aunque el $90 \%$ de las que se elaboran estén relacionadas con Colombia. Los corresponsales colombianos no forman parte de la plantilla de ninguna cadena colombiana, pero tampoco están contratados por IBER PRESS TV, son meros freelancers, periodistas a la pieza. Solo existía un contrato verbal entre empresa y trabajador. El redactor recibía 60 euros por noticia. En este contrato verbal se exigía al "contratado" disponibilidad absoluta, es decir, estar disponible los siete días de la semana. El envío de las informaciones a Colombia se realizaba a través de avión o vía satélite, sin editar, proceso que se completaba en Bogotá.

IBER PRESS TV asigna trabajos a colaboradores que no tienen formación académica ni están acreditados profesionalmente, lo que deriva en un detrimento en la calidad informativa, olvidándose así del respeto que toda empresa periodística debe a sus televidentes. Además, la agencia colombiana cubría la misma información para diferentes cadenas, utilizando los mismos planos, elaborados por una única cámara. Estos corresponsales nunca estuvieron respaldados por ninguna cadena colombiana, ni mucho menos podían exhibir acreditación alguna del medio al que iba destinado su trabajo. Es más la mayor parte del tiempo cubrían informaciones para diferentes cadenas a la vez, por lo que la fidelidad, objetividad, exclusividad y lealtad desaparecen cuando la información privilegiada, que proporciona un noticiero para la realización de una noticia en exclusiva, es compartida por el periodista con otras informativos para los que trabaja.

La diferencia horaria que existe entre Colombia y España supone que los "corresponsales" tengan dificultades para cubrir las noticias que se producen a última hora de la tarde en Madrid, ya que cuentan con poco tiempo para elaborarlas y enviarlas vía a satélite a la capital colombiana, puesto que la hora tope para su envío son las 12 de la noche hora española. 
En cuanto a la empresa mexicana se constata que ECO consultaba las informaciones aparecidas en los medios españoles, elaborando sus noticias $\sin$ introducir cambios sustanciales, lo que se puede considerar sencillamente como un plagio. Sus fuentes más fiables eran el diario "El País" y "Radio Nacional de España". Más del $80 \%$ de las noticias que producían se elaboraban copiando casi literalmente los textos del mencionado diario. Los temas a los que ECO da prioridad son los políticos, económicos y de terrorismo, por este orden. Dedicando tan solo un $5 \%$ a hechos ocurridos en España que tienen que ver con México.

El corresponsal mexicano no supervisa ni mantiene un control de los relatos elaborados en su propia sede, no sabe en qué trabaja el resto de sus compañeros. Sirva de ejemplo curioso que son los operadores de cámara de la empresa mexicana los encargados de editar las noticias, ya que cuentan con equipo para hacerlo y con el conocimiento del archivo, conocimiento del que carecen los periodistas. El operador de cámara, que en ECO realiza funciones que no le corresponden, corrige el texto del redactor aunque no esté cualificado para esta labor, ya que el corresponsal regresa a su despacho dejando a éste que escoja los planos y corrija el texto, en definitiva, que edite la noticia que se enviará a TELEVISA en México. De esta forma los redactores acaban siendo meros "recogedores" de la información, renunciando así a una de sus principales funciones como es la de dar forma y aplicar su criterio profesional al hecho informativo.

\section{ORGANIGRAMA DE LAS CORRESPONSALÍAS}

\section{ECO (México)}

\section{CORRESPONSAL JEFE \\ Alberto Peláez}

REDACCIÓN

CÁMARA

Patricia Alvarado.

Sandra Álvaro.

Cayetana Peláez.

\section{PRODUCCIÓN}

Rosa García G.

Yolanda Fernández G.

María del Mar Parra C.
OPERADORES DE

Fernando Ávila B. Juan Cobo L. Rafael Sáez O. Francisco Javier C. 


\section{IBER PRESS TV. (Colombia)}

CORRESPONSAL JEFE

Mauricio Hernández

REDACCIÓN
CÁMARA
Lina Grovas.
Beatriz Gájate.
Luis Fernando Rozo.
Hernández.

PRODUCCIÓN

Marta Olarte.

\section{OPERADORES DE}

John Becerra. Sergio Ortiz. Jorge

\section{Bibliografía básica}

BARROSOS GARCIA, Jaime. Proceso de la Información de actualidad en televisión. Instituto Oficial de Radio y Televisión. IORTV. RTVE. Madrid 1992.

FISHMAN, Mark. La fabricación de la noticia. Ediciones tres tiempos. Argentina, 1983.

GOMIS, Lorenzo. El Medio Media: La Función Política de la Prensa. Seminarios y Ediciones. Madrid 1974.

TUCHMAN, Gaye. La producción de la noticia. Gustavo Gilli. Barcelona 1978. 